\title{
PAUCI-IMMUNE ANCA-ASSOCIATED GLOMERULONEPHRITIS IN A PATIENT WITH SYSTEMIC LUPUS ERYTHEMATOSUS
}

Victor Pereira Mattos ${ }^{1, \star}$, Mariana Oliveira Miranda ${ }^{1}$, Alisson Regis de Santana ${ }^{1}$, Viviane Leal Novais ${ }^{1}$, Renata Borges de Lima ${ }^{1}$, Maria de Lourdes Castro de Oliveira Figueiroa ${ }^{1}$, Mittermayer Barreto Santiago ${ }^{1}$, Gustavo Luiz Behrens Pinto ${ }^{1}$

1.Universidade Federal da Bahia, Salvador (BA), Brazil.

*Corresponding author:victor_mattos@outlook.com.br

\section{BACKGROUND}

Lupus nephritis ( $L N$ ) is a common and severe manifestation of systemic lupus erythematosus ( $L E$ ) and is characterized by glomerular deposition of immune complexes. The formation of crescents is characteristically related to the presence of vasculitis. Antineutrophil cytoplasmic antibody (ANCA) can be found in patients with SLE and may play a role in the pathogenesis of crescent formation. The authors describe a patient with SLE whose kidney biopsy revealed a pauci-immune segmental proliferative glomerulonephritis with crescents.

\section{CASE REPORT}

A 34-year-old female patient diagnosed with SLE since 2007, with serositis, cutaneous and articular involvement, positive antinuclear antibody $1 / 640$ homogeneous nuclear pattern, and anti-dsDNA antibodies. She was using hydroxychloroquine $5 \mathrm{mg} / \mathrm{kg} / \mathrm{day}$, and her disease was in remission up to December 2020 when she presented a new malar rash and it was detected hypertension. On physical examination at that time, besides hypertension (blood pressure $180 \times 110 \mathrm{mmHg}$ ) and malar rash, there was symmetrical edema in her lower limbs. The rest of the physical examination was unremarkable. Laboratory work-up showed proteinuria of $2.1 \mathrm{~g} / 24 \mathrm{~h}$ and the presence of hematuria and pyuria on urinalysis. Complement fractions were diminished (C3: $45 \mathrm{mg} / \mathrm{dL}$; range 90-180 mg/dL; C4: 6 mg/dL; range $16-38 \mathrm{mg} / \mathrm{dL}$ ). Renal function was normal. ANCA was positive 1/80 with a perinuclear pattern. Renal biopsy revealed focal, segmental proliferative glomerulonephritis, pauci-immune, with cellular and fibrocellular crescents in $4 / 35$ glomeruli and fibrous crescents in $1 / 35$. Pulse therapy with methylprednisolone was started ( $1 \mathrm{~g} /$ day for 3 days) followed by prednisone and mycophenolate mofetil $3 \mathrm{~g} / \mathrm{day}$, and strict control of her blood pressure. There was normalization of the complement levels, a decrease of the proteinuria to $1 \mathrm{~g} / 24 \mathrm{~h}$, and resolution of hematuria and pyuria in the urinary sediment.

\section{CONCLUSION}

Pauci-immune NL is a rare form of renal involvement in SLE and, in the presence of ANCA, it is interpreted as a SLE/ANCA vasculitis overlap syndrome.

\section{KEYWORDS}

Glomerulonephritis, Lupus, ANCA. 